\section{Military Technical College Kobry El-Kobbah, Cairo, Egypt}

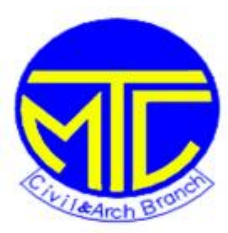

$9^{\text {th }}$ International Conference on Civil and Architecture Engineering ICCAE-9-2012

\title{
Alive Structures: A Modern Concept in Gardenpolis Architecture
}

\author{
Khaled Mohamed Dewidar*
}

\begin{abstract}
From the hanging gardens of Babylon to the Parisian "worker gardens," to the "community gardens" of New York going through Muscovite "vegetable squares", these new ideas, aware of the emergency to reduce our fuel consumption and the necessity to modify our behavior facing the climatic changes. Looking for a positive energetic assessment, the contemporary city aims within fifteen years at producing cleanly and intensively more energy than it consumes. It develops energy by biomass, photovoltaic cells, green walls, green roofs and other renewable energies. The architecture has to be in the service of this new green issues and approaches.

The twentieth century began with a flood of idealistic manifests from architects extolling the virtues of new building technologies to demater ialization and the loss of weight. Rarely did prophetic designers foresee the negative effects of industrialization. For the modernist pioneers, manufactured products were synonymous with liberty and unlimited opportunities. They never imagined the devastating consequences of these artifacts on global warming, declining resources, shrinking water supplies and overpopulation. A convincing argument for today would have to question everything the early theories extolled. Green architecture is about this proce ss. It advances architecture's most compelling dialogue by confronting the environmental predictions for the coming decade.
\end{abstract}
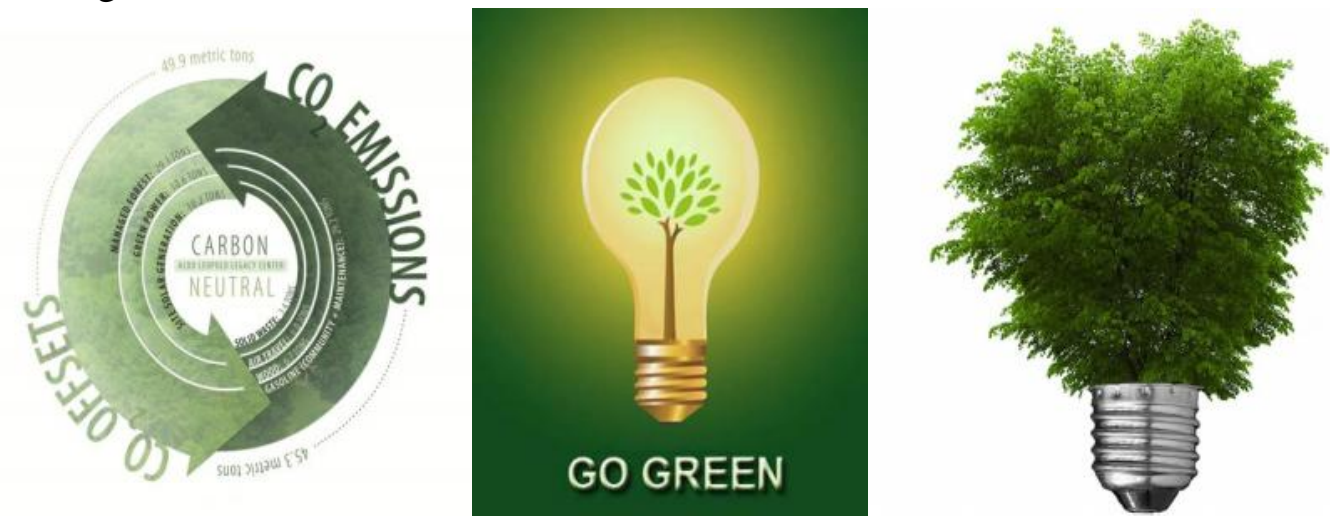

Figure 2: Carbon Dioxide Emission Rates Chart with the request for green technology

* Professor and Head of the Architecture Engineering Department, British University, Cairo Egypt 


\section{Green Technology}

Green technology is the key issue to avoid these doomsday scenarios. It shows us that when different ideas inspired by the science of ecology are used as a source of imagery, it expands not only the communicative power of the building art, but their social relevance as well. The new ecological architecture is the architecture using building performance as a guiding design principle and adopting a new list of performance -based priorities for the design of cities, buildings, landscapes and infrastructures. This architecture places broadly defined performance above form-making; it utilizes the digital technologies of quantitative and qualitative performance -based simulation to offer a comprehensive new approach to the design of the built environment. In the historical development from static to dynamic perception of space there is always a change in the concept of architectural style. Materials get to be lighter, structures more energetic and spaces get to be more dynamic. In it geometry, departs from Euclidian to Non Euclidian geometry. Architecture becomes liquid; fighting force would no longer be by mass but by inertia. Energy is the basic element of this new language, since it is capable of articulating the emerging concepts of and dynamic space in a new architectur al form. It is a new scenario in architecture that has to reshape our time. It is a major shift from technology to ecology. Our concern is how to reveal this hidden dimension to be a new reality and a new architectural start for the new millennium. It is a new architecture, designed by life and shaped by time. It is the marriage between biology, ecology. Science, technology, architecture and structure. It represents the end of typology and the rebirth of morphology. The gene of a historical building with the gene a new morphology is the Secret DNA code for a new potential in contemporary architecture .

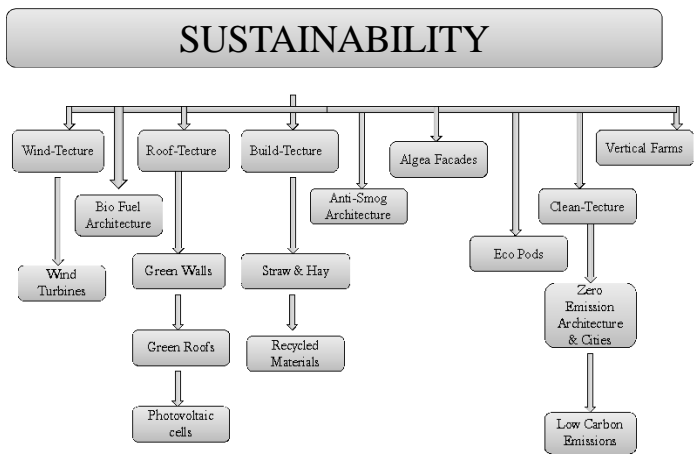

Fig 3: Sustainability Chart: Concepts and Ideas 
Our task is a zero emission architecture raising the debate between architectur e and nature, abstract and representation and finally reason and intuition. Architecture and the power of now will be reshaping our time. Green issues and approaches will activate the building in silence and absorb the increasing rates of pollution. Vertical gardens or living wall concepts offers numerous economic, social and environmental benefits such as greenhouse gas emission reduction, adaptation to climate change, air quality improvements, habitat provision and improved aesthetics. Despite these benef its a widespread market penetration of green façades over the world or the use of these greening technologies remains in its infancy.

The use of green façades is a good example where it is possible to link functions. Some benefits and linking functions of green façades are among other aspects:

- Energy savings through better insulation, causing lower inside temperature in summer and energy saving in winter.

- Protection of building materials and construction parts against UV light, rain and frost.

- An overgrown façade offers plants and smaller animals suitable habitats. That means it contributes to the improvement of the biodiversity in the built environment.

- Air purifying capacity (collection of particulate matter, carbon dioxide, nitrogen oxides).

- Improvement of the microclimate and the reduction of the so called "urban heat island" effect in urban paved areas.

- Less water to the sewage or surface water, because an amount of rainwater that falls on the roof can be used in living wall as well in hydroponics systems as well.

\section{Green Roof and Wall Technology}

Green roofs and walls are designed to be part of the landscape; they are attempts to blur the boundary between the building and its surroundings, as they raise the philosophy of architecture to new level of renewable sources. They represent a clean commitment to the environment
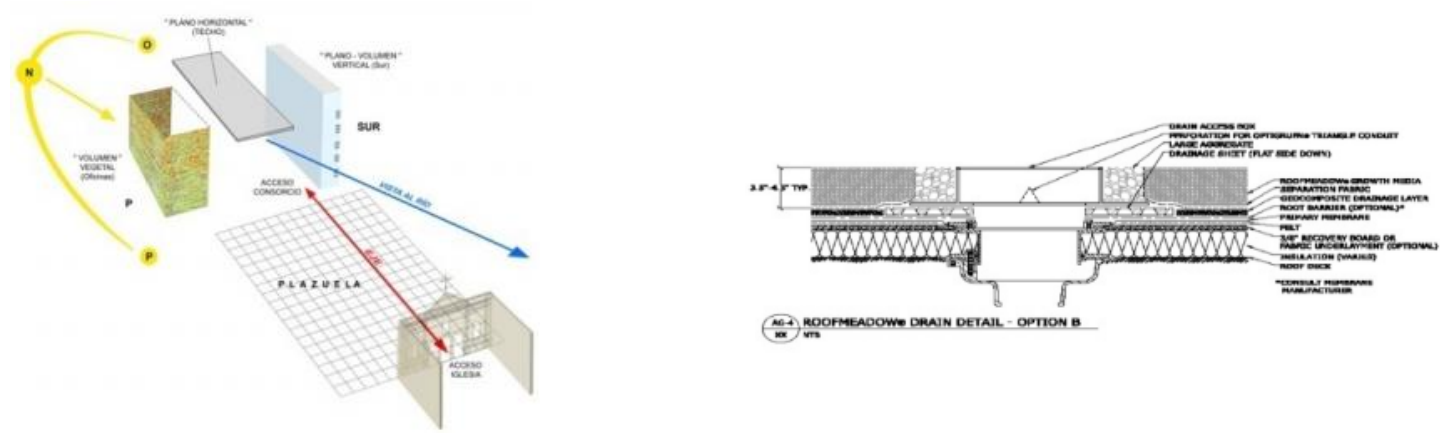

Fig 4: A Detail for a green wall and a green roof with its drainage outlets and insulation. 

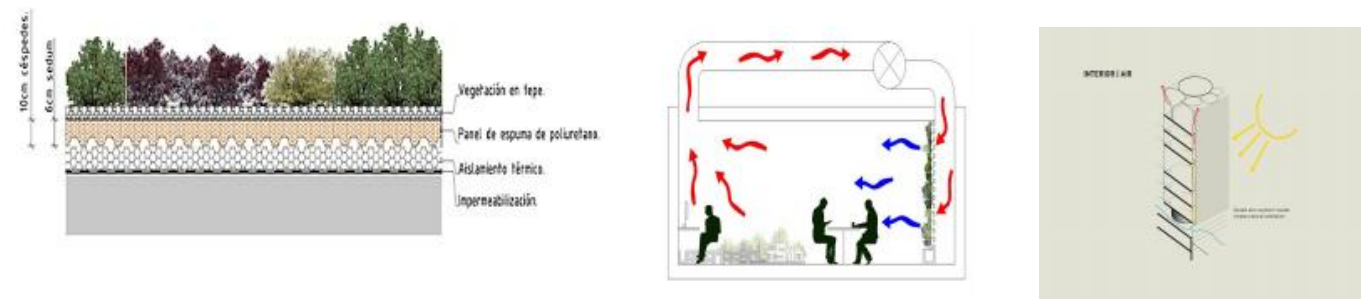

Fig 5: Green roofs implemented on an inclined plane
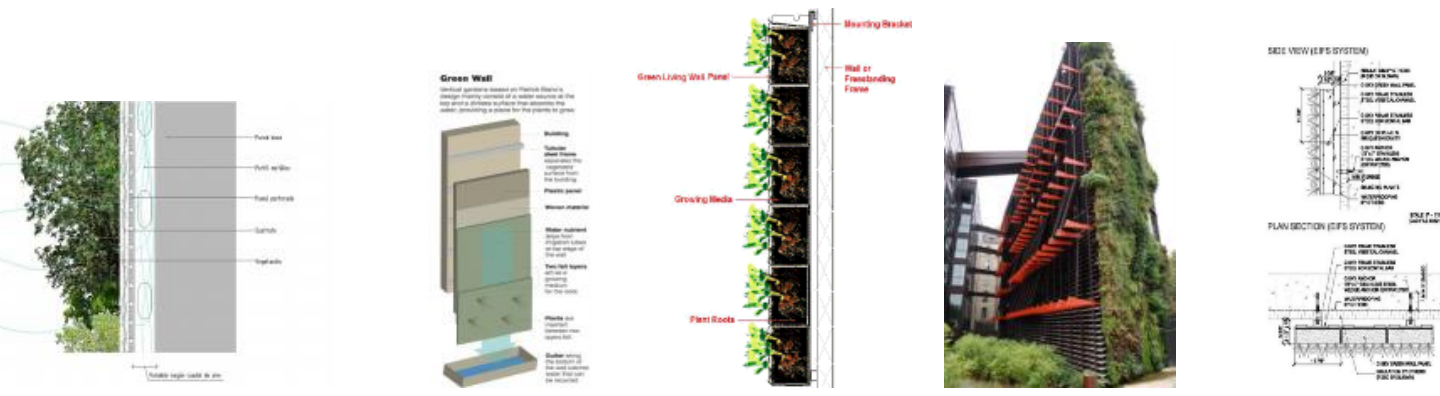

Fig 6: Green living lungs executed details.

\section{Conclusion}

Finally, the imagined future communities are integrated within the ever accelerating developments of the digital envir onment and ongoing rapid social change. Smog eating architectural roofs and walls presents a concrete architectural and urban proposal that entirely reconfigures, and consequently develops the existing "towers in the park" form. It forms a complex network of private, semipublic, and public spaces.

New forms of architecture and spatial structures, in addition to digital technologies is swiftly gaining in popularity and replacing the slab apartment buildings reminiscent of the "Hilbersheimer block that domin ated the urban landscape over the past 40 years. The towers in the park typology have been broadly applied in large cities. The park represents a public space, while the rising towers are an accumulation of individual dwelling units and demarcated private space.

Problematic in the engagement of these two static and seemingly opposing aspects is the lack of an intermediary space or structure that fosters the generation of spontaneous social interaction. Green roofs and wall technologies solving this problem by connecting and balancing the two elements. The creation of junctions between interior/exterior and public/private space on a variety of scales accommodates various residential activities and facilitates spontaneous social interactions.

\section{"Nature Does Nothing Wrong."}

\section{$\underline{\text { Aristotle }}$}

